\title{
A novel index in healthy infants and children subarachnoid space: ventricle ratio
}

\author{
A. Okur ${ }^{1}$, Ö. Küçük², S. Karaçavuş ${ }^{3}$, A. Yıldırım ${ }^{4}$, M.F. Erkoç ${ }^{5}$, Y. Erdoğann ${ }^{6}$, H.I. Serin ${ }^{1}$ \\ ${ }^{1}$ Department of Radiology, Bozok University Medical Faculty, Yozgat, Turkey \\ ${ }^{2}$ Department of Paediatrics, Yeditepe University Medical Faculty, Istanbul, Turkey \\ ${ }^{3}$ Department of Nuclear Medicine, Bozok University Medical Faculty, Yozgat, Turkey \\ ${ }^{4}$ Department of Radiology, Erciyes University Medical Faculty, Kayseri, Turkey \\ ${ }^{5}$ Department of Radiology, Sivas Numune Hospital, Sivas, Turkey \\ ${ }^{6}$ Department of Family Medicine, Bozok University Medical Faculty, Yozgat, Turkey \\ [Received 21 December 2012; Accepted 24 January 2013]
}

Background: The subarachnoid space (SAS) and ventricular width (VW) in normal infants and children were studied with ultrasonography to provide the objective measurement and define a normal range for these measurements. The additional aim was to determine the stable ratio as a SAS/VW.

Materials and methods: A total of 100 healthy subjects, including 48 males and 52 females, were studied. The cases were divided into 3 age groups: 0-6 months $(n=65), 7-12$ months $(n=24)$ and $>13$ months $(n=11)$. Transfontanel ultrasonography was performed in all the cases. SAS, WW and the SASIVW ratios were calculated. The study was approved by the ethical committee. All parents were informed about the sonographic examination and their approvals were taken.

Results: SAS was calculated as $3.1(0.5-6) \mathrm{mm}$ and WW was calculated as 3.6 (1.3-5) $\mathrm{mm}$. SAS/VW ratio was $0.9 \pm 0.3$. There was no statistically significant difference among SAS, WW and SAS/WW ratios in 3-97 percentile group ( $p>0.05$ ). Conclusions: Ultrasonography can be used as a practicable and reproducible modality in the measurement of SAS and VW in healthy children. It is a non-invasive method and allows for serial follow-up. SAS/WW ratio can be used as an index in healthy children. (Folia Morphol 2013; 72, 2: 142-146)

Key words: subarachnoid space, ventricular, healthy, children, ultrasonography

\section{INTRODUCTION}

Subarachnoid space (SAS) can be assessed by various imaging modalities, including computed tomography (CT), magnetic resonance imaging and ultrasonography (US) $[5,6,8,9,11-13]$. US is the method of choice and most commonly used modality [9]. It is also non-ionising, inexpensive and reproducible. SAS and VW have variations in healthy children, resulting in difficulty in the assessment [9].
In the present study, we aimed to identify a normal range by measuring SAS and VW and to prospectively investigate the feasibility of the new index (SAS/VW) with ultrasound in healthy infants and children.

\section{MATERIALS AND METHODS}

Overall, 100 healthy cases (48 boys and 52 girls) were included into the study. The cases were assigned into 3 age groups: $0-6$ months $(n=65)$, 
Table 1. Percentil groups of subjects according to head circumference, height and weight

\begin{tabular}{lccc}
\hline Percentile & Head circumference $(\mathbf{n})$ & Body height $(\mathbf{n})$ & Body weight (n) \\
\hline$<3$ & 4 & 5 & 2 \\
$3-50$ & 55 & 57 & 45 \\
$50-97$ & 41 & 38 & 47 \\
$>97$ & - & - & 6 \\
Total & 100 & 100 & 100 \\
\hline
\end{tabular}

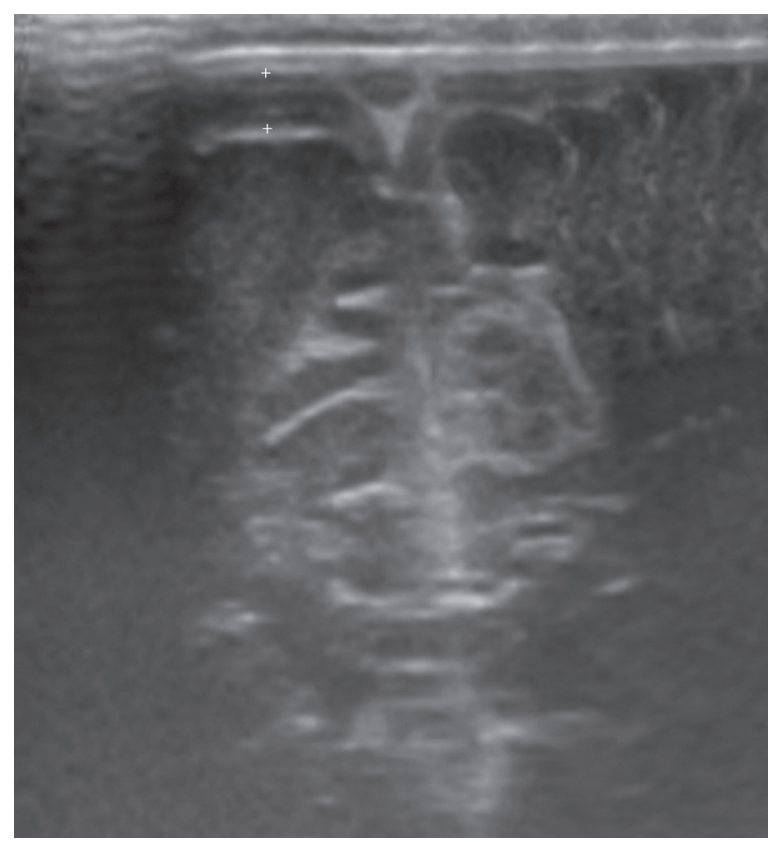

Figure 1. Coronal sonographic view of normal subarachnoid space. The subarachnoid space is measured in perpendicular fashion, with electronic caliper, from the edge of the sagittal sinus to the surface of the cortex.

7-12 months $(n=24)$ and $>13$ months $(n=11)$. All the cases were younger than 19 months of age. Only healthy children were included into the present study. Children with any disease (e.g. gastroenteritis, macrocephaly, prematurity) that may affect measurement of head circumference or subarachnoid distance and cases in which US evaluation revealed disorder, were excluded. This study was approved by institutional ethical committee and all parents gave the informed consent (Approval no: 10/4; Approval date: 23.02.2012).

The cases were classified into percentile groups $(<3 \mathrm{P}->97 \mathrm{P})$ according to head circumference, weight and height (Table 1).

All the sonographic evaluations were performed through anterior fontanel in a supine position by an experienced radiologist with 7-12 $\mathrm{MHz}$ linear and

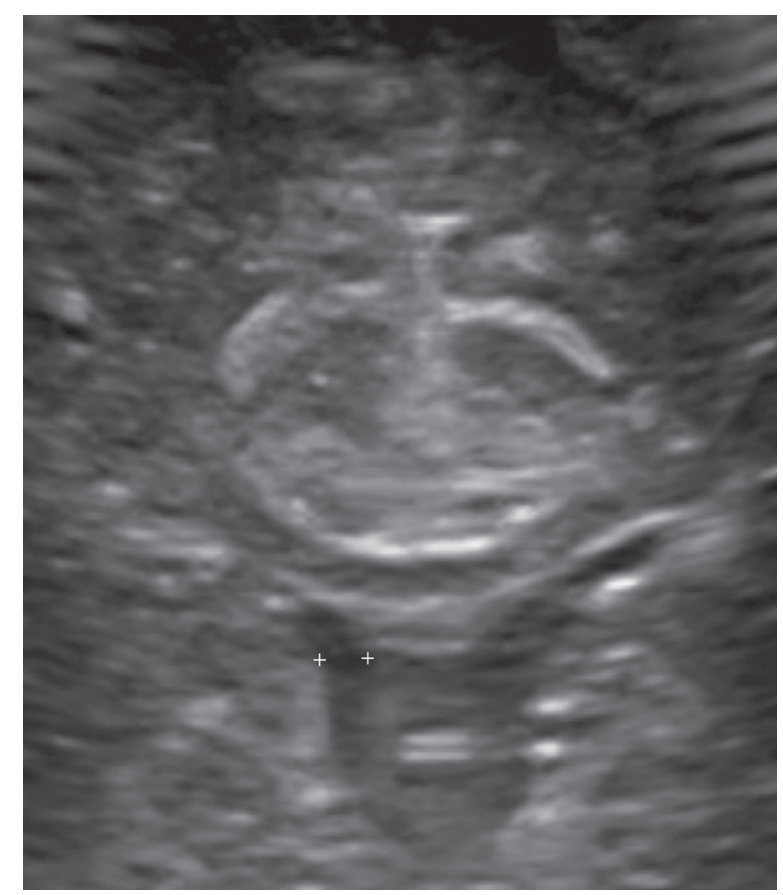

Figure 2. Coronal sonographic view of normal ventricular width.

4.5-5 $\mathrm{MHz}$ convex transducer (Aloka alfa 6, Japan). No sedation was employed in any of the cases. Sonographic measurements were performed at coronal plane at the level of foramen of Monro. SAS measurements were obtained by bilaterally measuring shortest distances between calvarium and cortex and by averaging these 2 measurements (Fig. 1). VW was obtained by measuring left and right anterior ventricular horns at Monro's foramen level and by averaging these 2 measurements (Fig. 2). Then, SS/ VW ratio was calculated.

\section{Statistical analysis}

Statistical analysis was performed by using SPSS version 17.0 statistical software. Numeric variables were presented as mean \pm standard error, while categorical variables as number and percentage. After the 
Table 2. Mean values of head circumference, height and weight of 3-97 percentile group

\begin{tabular}{lccc}
\hline & Head circumference [mm] & Body length [mm] & Body weight [kg] \\
\hline Subarachnoid space (SAS) & $3.1 \pm 1.24$ & $3.1 \pm 1.24$ & $3.1 \pm 1.27$ \\
Ventricular width (VW) & $3.6 \pm 1.02$ & $3.6 \pm 1.03$ & $3.6 \pm 1.03$ \\
SAS/NW & $0.9 \pm 0.3$ & $0.9 \pm 0.3$ & $0.9 \pm 0.3$ \\
\hline
\end{tabular}

Table 3. Cerebrospinal fluid spaces sizes [mm] according to age [month]

\begin{tabular}{lccc}
\hline & $\mathbf{0 - 7}(\mathbf{n}=\mathbf{6 5})$ & $\mathbf{7 - 1 2}(\mathbf{n}=\mathbf{2 3})$ & $>\mathbf{1 3}(\mathbf{n}=\mathbf{1 2})$ \\
\hline Subarachnoid space (SAS) & $3.06 \pm 1.14$ & $3.4 \pm 1.4$ & $2.7 \pm 1.3$ \\
Ventricular width (VW) & $3.4 \pm 1.03$ & $4.1 \pm 0.7$ & $3.2 \pm 1.11$ \\
SAS/NW & $0.9 \pm 0.3$ & $0.80 \pm 0.3$ & $0.9 \pm 0.4$ \\
\hline
\end{tabular}

Table 4. Cerebrospinal fluid spaces sizes according to body height [mm]

\begin{tabular}{lccc}
\hline & \multicolumn{3}{c}{ Groups of body height [percentil] } \\
\cline { 2 - 4 } & $\mathbf{3}$ & $\mathbf{3 - 5 0}$ & $\mathbf{5 0 - 9 7}$ \\
\hline Subarachnoid space (SAS) & $2.30 \pm 0.9$ & $2.98 \pm 1.3$ & $3.36 \pm 1.0$ \\
Ventricular width (VW) & $2.70 \pm 0.6$ & $3.45 \pm 1.1$ & $3.85 \pm 0.8$ \\
SAS/NW & $0.84 \pm 0.2$ & $0.88 \pm 0.4$ & $0.91 \pm 0.2$ \\
\hline
\end{tabular}

assessment of distribution, Student $t$ test was used to compare continuous variables with normal distribution, while Mann-Whitney $U$ in the comparison of variables without normal distribution. Categorical variables were assessed by $\chi^{2}$ test. Pearson correlation test was performed to determine the correlation between numeric variables. Alpha significance level was accepted as 0.05 ( $p<0.05)$.

\section{RESULTS}

Of all the cases, 65 children were at 0-6 months of age and 24 children were at 7-12 months of age; 11 children were at 13 months of age. Values of head circumference, body weight and height were usually between 3 and $97 \mathrm{P}$ (Table 1).

Table 2 presents SAS measurement, WW and SAS/NW ratios in 3-97 $\mathrm{P}$ group according to head circumference, height and weight.

Overall, mean SAS measurement was found as $3.1(0.5-6) \mathrm{mm}$, mean $\mathrm{VW}$ as $3.6(1.3-5) \mathrm{mm}$ and SAS/NW ratio as $0.9 \pm 03$. Mean SAS measurements were $3.2 \pm 1.2$ and $3.0 \pm 1.2 \mathrm{~mm}$ in boys and girls, respectively, while mean $\mathrm{VW}$ values were $3.6 \pm 0.9 \mathrm{~mm}$ and $3.5 \pm 1.1 \mathrm{~mm}$ in boys and girls, respectively. SAS/VW ratio was $0.9 \pm 0.3$ in both boys and girls. No significant difference was found between boys and girls regarding SAS and VW measurements and SAS/VW ratio ( $p>0.05$ ).

There was no significant difference between age groups regarding SAS and VW measurements and SAS/VW ratio ( $p>0.05$ ) (Table 3 ).

When mean SAS and SAS/VW ratios were considered according to height percentiles, no significant difference was found between the groups ( $p>0.05$ ). A difference was observed in VW measurements between $3 \mathrm{P}$ and 50-97 $\mathrm{P}$ groups, but it did not reach a statistical significance $(p=0.48)$ (Table 4).

When mean SAS and VW were considered according to head circumference percentiles, a significant difference was detected between 3-50 P and 50-97 P groups ( $p<0.05$ and $p<0.001$, respectively). No significant difference was observed in SAS/NW ratio (Table 5).

When mean SAS and VW were considered according to weight percentiles, there was a significant difference between 3-50 $\mathrm{P}$ and 50-97 $\mathrm{P}$ groups 
Table 5. Cerebrospinal fluid spaces sizes according to head circumference [mm]

\begin{tabular}{lccc}
\hline & \multicolumn{3}{c}{ Groups of head circumference [percentil] } \\
\cline { 2 - 4 } & $\mathbf{3}$ & $\mathbf{3 - 5 0}$ & $\mathbf{5 0 - 9 7}$ \\
\hline Subarachnoid space (SAS) & $3.67 \pm 1.04$ & $2.70 \pm 1.17$ & $3.55 \pm 1.17$ \\
Ventricular width (VW) & $3.40 \pm 1.4$ & $3.20 \pm 0.10$ & $4.0 \pm 0.9$ \\
SAS/NW & $1.17 \pm 0.35$ & $0.87 \pm 0.32$ & $0.91 \pm 0.34$ \\
\hline
\end{tabular}

Table 6. Cerebrospinal fluid spaces sizes [mm] according to body weight

\begin{tabular}{lccc}
\hline & \multicolumn{3}{c}{ Groups of body weight [percentil] } \\
\cline { 2 - 4 } & $\mathbf{3}$ & $\mathbf{3 - 5 0}$ & $\mathbf{5 0 - 9 7}$ \\
\hline Subarachnoid space (SAS) & $2.85 \pm 0.2$ & $2.60 \pm 1.3$ & $3.47 \pm 1.1$ \\
Ventricular width (VW) & $2.30 \pm 0.9$ & $3.30 \pm 1.1$ & $3.92 \pm 0.8$ \\
SAS/NW & $1.30 \pm 0.5$ & $0.82 \pm 0.3$ & $0.91 \pm 0.2$ \\
\hline
\end{tabular}

( $p<0.05$ ). No significant difference was found in SAS/ NW ratio between 3-97 P groups ( $p>0.05$ ) (Table 6).

\section{DISCUSSION}

SAS measurements varies according to the method used in the studies [11]. In studies on healthy children, SAS was found as 1.9-5.7 mm [4, 5, 14]. Libicher and Tröger [9], and Frankel et al. [4] found these measurements smaller than $4 \mathrm{~mm}$ and $3.5 \mathrm{~mm}$, respectively. They suggested that $3 \mathrm{~mm}$ should be the upper limit over 95 P [9]. Sabouri et al. [14] reported that mean values for SAS was 1-4 mm and for VW was 4.5-8 mm. Width of lateral ventricle is accepted as normal if it is smaller than $10 \mathrm{~mm}$ at the level of Monro's foramen [7]. In our study, mean SAS and VW measurements were found as $3.1(0.5-6) \mathrm{mm}$ and $3.6(1.3-5) \mathrm{mm}$, respectively. As suggested in studies, there is no standard value for SAS and ventricular measurements. Therefore, we calculated SAS/VW ratio, given the idea that a constant ratio should help us to determine a normal value. No significant difference was detected in SAS/VW ratio $(0.9 \pm 0.3)$ in 3-97 P group according to age, weight and head circumference. This suggests that SAS/VW ratio should be used in healthy children.

In a study using CT by Fukuyama et al. [5], it was suggested that care should be taken since wide subarachnoid space may be physiological in children younger than 1 year of age. Pedersen et al. [13] conducted a study in healthy children younger than 3 years of age by using $C T$ and detected that interhemispheric fissure and Sylvian fissure were wider than normal. Maytal et al. [10] cited an age-related external hydrocephaly in infants, which returns to normal without treatment up to 2-3 years of age with the opening of cranial sutures. In our study, SAS and VW values increased until 13 months of age and decreased in those older than 13 months of age.

In one study, it was suggested that the development of brain and gyral pattern were accompanied by SAS development, which surrounds these structures. This was explained by increased cerebrospinal fluid (CSF) production in response to growing brain [8]. The studies reported that there was a close relationship between head circumference and brain development and that SAS measurement might be more valuable in the assessment of brain development than head circumference $[1,3]$. In pursuance of the literature, SAS measurements and VW values were found to be wider in cases between $50 \mathrm{P}$ and $97 \mathrm{P}$ according to head circumference herein.

In our study, SAS, VW and SAS/VW values were individually estimated in accordance with head circumference, height and weight percentiles and no difference was found in 3-97 $\mathrm{P}$ group.

Excessive CSF fluid is absorbed by arachnoid villi in particular age groups [2]. Thus, there may be varying values for SAS and ventricular measurements. We believe that it should be helpful to keep this fact in mind when assessing SAS measurements. For this reason, SAS/VW ratio may be of help, however, it should be supported by larger studies. 


\section{CONCLUSIONS}

US is the practicable and reproducible modality in the measurement of SAS and VW in healthy infants and children. It has advantages of being non-invasive and enabling serial measurements. SAS/NW ratio may be used as an index for healthy children.

\section{REFERENCES}

1. Armstrong DL, Bagnall C, Harding JE, Teele RL (2002) Measurement of the subarachnoid space by ultrasound in preterm infants. Arch Dis Child Fetal Neonatal Ed, 86: 124-126.

2. Barlow CF (1984) CSF dynamics in hydrocephalus: with special attention to external hydrocephalus. Brain Dev, 6: 119-127.

3. Dobbing J, Sands J (1978) Head circumference, biparietal diameter and brain growth in fetal and postnatal life. Early Hum Dev, 2: 81-87.

4. Frankel DA, Fessell DP, Wolfson WP (1998) High resolution sonographic determination of the normal dimensions of the intracranial extraaxial compartment in the newborn infant. J Ultrasound Med, 17: 411-415.

5. Fukuyama Y, Miyao M, Ishizu T, Maruyama H (1979) Developmental changes in normal cranial measurements by computed tomography. Dev Med Child Neurol, 21: 425-432.

6. Govaert P, Pauwels W, Vanhaesebrouck P, De Praeter C, Afschrift M (1989) Ultrasound measurement of the subarachnoid space in infants. Eur J Pediatr, 148: 412-413.
7. Johnson ML, Mack LA, Rumack CM, Frost M, Rashbaum C (1979) B-mode echoencephalography in the normal and high risk infant. Am J Roentgenol, 133: 375-381.

8. Kleinman PK, Zito JL, Davidson RI, Raptopoulos V (1983) The subarachnoid spaces in children: normal variations in size. Radiology, 147: 455-457.

9. Libicher M, Tröger J (1992) US measurement of the subarachnoid spce in infants: normal values. Radiology, 184: 749-751.

10. Maytal J, Alvarez LA, Elkin CM, Shinnar S (1987) External hydrocephalus: radiologic spectrum and differentiation from cerebral atrophy. Am J Roentgenol, 148: 1223-1230.

11. McArdle CB, Richardson CJ, Nicholas DA, Mirfakhraee M, Hayden CK, Amparo EG (1987) Developmental features of the neonatal brain: MR imaging. Part II. Ventricular size and extracerebral space. Radiology, 162: 230-234.

12. Narli N, Soyupak S, Yildizdas HY, Tutak E, Ozcan K, Sertdemir Y, Satar M (2006) Ultrasonographic measurement of subarachnoid space in normal term newborns. Eur J Radiol, 58: 110-112.

13. Pedersen H, Gyldensted M, Gyldensted C (1979) Measurement of the normal ventricular system and supratentorial subarachnoid space in children with computed tomography. Neuroradiology, 17: 231-237.

14. Sabouri S, Khatami A, Shahnazi M, Tonekaboni SH, Momeni A, Mehrafarin M (2011) Ultrasonographic measurement of subarachnoid space and frontal horn width in healthy Iranian infants. Iran J Child Neurology, 5: 9-14. 